\title{
Subduing Cultural Stereotype \& Ethnocentrism in Business Organizations: A Soft Skills Stance
}

\author{
Mitashree Tripathy \\ [Orissa Engineering College, Bhubaneswar, Odisha, India, mitashreetripathy84@gmail.com]
}

Diterima: 06 Februari 2019

Direview: 27 Mei 2019

Diterbitkan: 31 Juli 2019

Hak Cipta @ 2019 oleh Penulis (dkk) dan Jurnal Sosial Humaniora (JSH)

*This work is licensed under the Creative

Commons Attribution International License (CC BY 4.0).

http://creativecommons.org/licenses/by/4.0/ Open Access
Subject Areas: Culture

\begin{abstract}
Business organizations are highly dependent on culture and communication that define the essence of their existence. Researches indicate that while some organizations have successfully placed themselves in the global market places, there are still others who have deteriorated because of weak communication or insufficient assimilation with other organizations of different cultures. Recent studies argued that the accomplishment of the global business depends on successful cross cultural communication. This paper studies the role of cross cultural communication and the barriers that obstruct cross cultural effectiveness in business. The paper especially focuses on the cultural stereotype and ethnocentrism as the most powerful barriers in cross cultural communication and proposes solutions towards the relevance of soft skills in overcoming the barriers and ensuring success in business in unprecedented ways and their development in cross cultural management.
\end{abstract}

Keywords: Communication; Culture; Cross Cultural Communication; Barriers; Soft Skills; Stereotype, Ethnocentrism

\section{Introduction}

The scope of business organizations has expanded rapidly most essentially in the recent decades. The theory of global economy has increased customer consciousness, identified fresh standards and system of operations, and also amplified the emergency for national and corporate mutuality. The concept of fast evolution of business dealings has provided innumerable multinational organizations to explore ample opportunities around the world. What keeps these business organizations moving is communication among each other which is crucial and which connects each one of them in order to achieve a competitive advantage by successfully explaining their products and services and the many ways they differ in each organization. Communication is one the most indispensable tool for individuals to express themselves. It merely seems to be a process of exchange of ideas and in response receiving feedback. Cooley writes "by communication one means the mechanism through which human relations exist and develop-all symbols of the mind, together with the means of conveying them through space and preserving them in time. It includes the expression of the face, attitude and gesture, the tones of the voice, words, writing, printing, railways telegraphs, telephones, and 
whatever else may be the latest achievement in the conquest of space and time" (Cooley 1998:100).

Rosengren elucidates that "the word 'communicate' is historically related to the word 'common'. It stems from the Latin verb communicare, which means 'to share', 'to make common' and which in turn is related to the Latin word for common: communis. When we communicate we make things common. We thus increase our shared knowledge, our 'common sense' the basic precondition for all community" (Rosengren 2000:1).

The word culture around the world has various definitions. "In most western languages the word culture is usually used in the sense of 'civilization' or 'refinement of the mind"” (Gerritsen 2018:28). In other words the evolution of humans and their studies make us understand that culture constitutes activities that distills minds and teaches us our essence of existence. Activities like meeting, greeting, eating, living, dressing, expressing emotions and thousands of other actions and doings are culture generated. Overall, the rituals of culture primarily signify communication in every way. Interestingly, communication with each other inside the same culture can also bring about misunderstanding or misinterpretation. Then it is obvious that communication outside the culture or communicating with others from different cultures can become more complicated and intriguing. However, communication is as inevitable as breathing and cannot be substituted.

Communication and culture are thus the robust aspects in business organizations. Again, interworking on manifold approaches towards identifying, comprehending, appreciating and accepting the concept of diversity in culture and being aware of one's own identities are exactly what many authors have been writing upon. Many authors however, hold an equal view towards cross cultural communication and intercultural communication and they believe that both the trms can be used relatively. Gudykunst however, opines "cross cultural involves comparisons of communication across cultures and intercultural communication involves communication between people from different cultures" (Gudykunst 2003:1). In the same context Gonzalez cites an example of celebrating birthdays by Brazilians and Mexicans. Gonzalez studies "Mexicans love to focus on cooking and sharing of the food while Brazilians love the dancing (...) As a Mexican I may complain that there's not enough food but I love the dancing and join the group". (Gonzalez 2011). Hence, both the studies of communication although are culturebased are comparatively different from each other.

Neulip provides reasons and necessity for the intercultural communication by citing an example in his book Intercultural Communication: A Contextual Approach on the incident that took place in 2001 when a US navy flight clashed against a fighter jet of China that almost damaged the US plane. However it was successful in landing safe at the Chinese air base but was apprehended by the Chinese military. The US on the other hand conflicted over the reason behind the accident. Both the parties didn't stop but blamed each other for the incidence which continued for months altogether. Both public and political pressure mounted as nothing could be sorted out to provide release to the US crew which was still under the Chinese captivity. Finally a grievance letter was issued to the Chinese minister to communicate to the Chinese military and to the family of the pilot regarding their loss. Also that they were apologetic invading into the airspace that belonged to China. At 
the same time they ensured that they did not use the word apology in the letter. However, during announcement the Chinese officials interpreted the “double 'very sorry' as 'shenbiao qianyi' which in Chinese means a deep expression of apology or regret not used unless one is admitting wrongdoing and accepting responsibility for it" (Neulip 2017:3-4). Only on that pedestal that is the letter and its translation that the Chinese agreed to discharge and set free the US crew. Later John Pomfret affirmed "in the end it was a matter of what the US chose to say and what China chose to hear" (4). Hence the necessity of intercultural communication arose due to reasons like conflicts further inflamed by the various reasons again like religious, racial, national and sometimes interpersonal like social and personal views. However, the basis remains the same that is one should select only those words that the other party desires to listen. Only then a successful communication takes place.

The significance of communication in business organization is even more crucial. Business organizations are large platforms where employees share their opinions, interchange messages, give and take information and attempt to understand each other for successful running of the company. Employees work together under one common roof in order to achieve one common goal. Every business organization runs for three main aims. i) In order to create a brand image. ii) To stay ahead of competition. iii) To earn profits. Hence it is obvious that employees along with the employers have to work together to achieve all the three aims and goals. For successful running of the organization, business communication is a must. Means understands "business communication is sending and interpreting messages related to products, services, or activities of a company or an organization. Effective communication is important for business success" (Means 2009:6).

In business organizations to be successful there must be "an environment that energizes and provides encouragement to employees to accomplish tasks by encouraging genuine openness and effective communication. Organizational communication is concerned with the movement of information within the company structure" (Lehman and Dufrene 2010:8). Whatever position an individual might be in the success of the organization is dependent on the communication level with each other. Notwithstanding the ability to communicate promotes misunderstanding and disarray in various situations.

Business organizations have a broad spectrum to expand. Hence, a large number of business organizations spread out worldwide engrossing various cultures. While the need to develop across cultures has been an important criterion to be successful it has become equally significant to communicate across cultures effectively. Business organizations are making cultures come close to each other and fulfilling their needs to widen up. Niemeier, Campbell and Dirven view that "culture is not a definite entity, but a conceptualization in our brains (...)" (Niemeier, Campbell and Dirven 1998:3). A culture can be referred to as a collective set of different patterns including lifestyles, beliefs, habits, customs, dressing sense, food habits, tradition and many more. Interestingly, while doing business across various cultures it is essential to understand that only the appropriate way of communication among the organizations would carry forward success.

Hence, in business when cultures communicate in order to bring prosperity to business 
organizations it is referred to as cross cultural communication. While it seems easy on one level it is however different and difficult. But what increases the risks of understanding in communication when cultures communicate with each other? Maude claims its mostly cultural noise that "impediments to communication that occur when people from different cultures interact-leads people to misunderstand each other's intentions and meanings" (Maude 2016:19).

Managing and accepting cultural differences is not an easy task. Merkin in his book Saving Face in Business: Managing Cross Cultural Interactions writes how one would succeed at cross cultural communication. He asserts one must attempt successful cross cultural communication "without violating others' assumptions and rituals, we must be able to read and understand the meanings they convey through their behavior while communicating to preserve face for all" (Merkin 2017:3)

Laroche and Yang tend to give up few solutions in order to develop cross cultural skills. They are of the view that awareness is one of the best solutions of the problems in cross cultural communication. They write "when we know we are dealing with a cultural difference, we react differently. Rather than blaming the other person or ourselves for not measuring up we look for solutions to a common problem. Showing interest for and learning about our counterpart's cultural background usually helps smooth relationships" (Laroche and Yang 2014:52).

This paper studies the importance of cross cultural communication in business and the barriers that obstruct cross cultural communication. This paper also studies in details the importance of soft skills in determining and overcoming the barriers in cross cultural communication hence successfully promoting the same and effectively communicating.

\section{Method}

\section{Barriers in Cross Cultural Communication}

Cross culture is even a broader arena than culture where communication is even more multifaceted and fascinating. A slight miscommunication can give rise to troublesome consequences which are sometimes irreparable. Cross cultural communication is a study that analyses how people from different cultures when come closer to each other for one common purpose communicate with each other. It is a field of study which discusses the similarities and the comparisons of communication among differing cultures and what efforts do individuals give in order to communication. When cultures become different, variations arise in the values, thoughts, lifestyles, body languages, habits, beliefs, customs, eating and dressing styles and many more. Hence, cross cultural communication studies even if with varied cultural rituals do individuals accept or diverge from communicating with each other from different cultures. A great deal of effect is also noticed in business sectors. Let's take for example, an employee of Indian origin works for Samsung in Dubai. This is one of the best examples of cross cultural communication. Let's understand how. The Indian origin employee who is born and brought up in India and is enrich with Indian culture. The employee is infused with the rituals, habits, customs and values of India. Now this employee works for a South Korean company Samsung whose headquarters and governing body are South Korean culture bound. Next, the employee is placed in Dubai where both the company and the employee follow the local laws. 
When carefully analyzed one would understand that there are three cultures coming intact with each other where everyday where cross cultural communication takes place. But if there is a slight mismanagement of communication especially when the Indian origin employee doesn't accept the thoughts and beliefs of the company or the locality the company is placed in or vice-versa there takes place barrier in communication which entirely breaks down the communication process.

So what can be possible reasons behind the disintegration of communication while dealing cross culturally? Studies define the reasons to be barriers and following are the possible barriers in cross cultural communication. Renowned authors and researchers and business analysts confirm that barriers to cross cultural communication are many including stereotypes and prejudices, ethnocentrism, non verbal communication, anxiety and avoidance, assumptions and many more. However, this paper would focus only on two chief barriers that hinder the communication process while dealing business cross culturally.

\section{Cultural Stereotype in Business}

Maude provides a very good example on stereotypes and prejudices. Let's understand. Maude writes "A black store manager for a North American retail chain attends a one-day management seminar on discrimination in the workplace. During one of the sessions participants describe any experience they have had of discrimination. During this session the store manager says that he attends many company meetings and that in many of them his white colleagues bombard him with aggressive questions. They do this, he claims, to challenge his competence and his ability to run a large store profitably. They think blacks' ability to apply sound accounting principles and statistical techniques is questionable to say the least" (Maude 2016:69). The concept of stereotypes and prejudices arise when and where one group generalizes another and strongly believes that the other group is meant to be dominated and ill treated. In the above example the white colleagues do accept that the black colleague may have abilities. As the whites have a pre conceived notion that blacks are subjects to negativity, inferiority and menial, they ought to be discriminated. Hartley and Bruckmann assert "A stereotype is a generalization about a group of people based upon their group membership: to stereotype is to assign identical characteristics to any person in a group, regardless of the actual variation among members of that group (Hartley and Bruckmann 2002:49). In stereotyping people often relate the cultural background of a group with the individual's personality within the group which gives rise to discrimination and obstructs communication process.

In business communication also when an employee meets another employee for the first time, the mind connects with images of the employee's cultural background rather than his personality. This creates less or no communication at all. Goldman and Shapiro in their book The psychology of Negotiations in the 21st Century Workplace: New Challenges and New solutions provide another example of cultural stereotyping. They provide an example of a communication between an American manager and a Saudi counterpart. In a meeting when both of them meet and "the Saudi counterpart wears a thawb and ghutra an iqal which is the traditional Saudi clothing, the American negotiator might assume the counterpart to be typically Saudi" (Goldman and Shapiro 2012:276). However, the case might be far 
different from what is seen. The Saudi counterpart may have received education in the west and that the outlook carried towards business relationships is more Western than Middle Eastern.

In business communication especially when cultures meet body language, plays a pivotal role. It can be both restrained and deliberate sent or unsent both consciously or unconsciously. "In Mediterranean cultures, it is common to exaggerate signs of grief or sadness, while Chinese and Koreans prefer to conceal emotions and not engage in animated facial expressions. In Thailand, a smile is a sign of friendliness; in Korea and Japan it can be a sign of shallowness" (Steers, Nardon, \& SánchezRunde 2011:219). Let us assume that during a business meeting people from Mediterranean culture and Asian culture including Chinese and Koreans sit together. Mediterranean people are unhappy due to certain reasons. As they are quite expressive in their signs of emotions this may not suit the Chinese and the Koreans as they are quite shy and not very expressive. Also, while in Japan, a smile is a sign of happiness and at times can be used to conceal anger, embarrassment and other negative emotions. In business dealings Americans would “open conversations with a smile and to keep smiling. Russians tend to start out with grim faces, but when they do smile; it reflects relaxations and progress in developing a good relationship" (Ting-Toomey, Gu, \& Chi 2007:121-122)

In western cultures for example United Nations, Switzerland, Scandinavia, Germany is recognized as punctual and they don't waste time. Mainly during business meetings these countries don't believe in beating around the bush and come straight to the point. While at the same time there are cultures who construct time for doing multiple works at one time. They believe in multitasking even during business dealings. Latin America, Southern European, North Europeans and Northern Americans are few examples. Let us presuppose while in a meeting business managers from Latin America and Germany sit together to discuss something grave. While the German manager directly talks about the important point for discussion the Latin American attends calls, talks to the assistant, diverts from the topic, has coffee and says hello to his family through video conferencing. This attitude may seem strange to the German for whom work is very important. The casual behavior of the Latin American may not permit the German to continue doing business with him.

Clearly the act of stereotyping is harmful for communication and in turn hazardous for business. Corporations, stake holders, consumers need to make a note of the various effects stereotyping and generalizations charge on each other Carroll writes "when important stakeholders hold negative stereotypes of a corporation, it is crucial to develop communication campaigns to change such perceptions. Even if stakeholders hold positive stereotypes, when such views considerably deviate from reality, these stereotypes may still be problematic since stake holders may have unrealistic expectations that are difficult for organizations to meet" (Carroll 2016:807).

\section{Cultural Ethnocentrism in Business}

After stereotyping, ethnocentrism is regarded as one of the most powerful barrier in cultural communication. In the book Research in Organizational Behavior: An Annual Series of Analytical Essays and Critical Reviews Staw and Kramer quote what Sumner had described 
ethnocentrism as in 1906. They write "Sumner described ethnocentrism as the technical name for this view of things in which one's group is the centre of everything and all others are scaled and rated with reference to it" (Staw and Kramer 2005:237). In other words, a group or a set of people attach to them an air of pride and vanity and hoot their superiority while completely disregarding the views, beliefs and opinions of other set of people or group. In a nutshell, the other set of people are completely out casted. In such a practice a negligible or negative identification or insensitivity towards others cultures and their habits are overtly expressed.

Let us understand this with the following examples. Many companies hold ethnocentric practice as they set aside executive positions for the people whether deserving or not but who belong to their group and thereby barring such significant positions from people who do not belong to their clan even though they deserve them. Such an approach can literally hamper the value and ethics of the barred staff and can also affect tremendously on the productivity of the workers. This could also lead to disharmony among the entire staff as Dlaby and Scott affirm that "natives of the parent country might not be culturally sensitive enough to manage local workers well" (Dlaby and Scott 2010:276).

Studies reveal that the ethnocentric attitude can be depicted both consciously and unconsciously. Whereas the former may include actions like not accepting the customs of another culture, or disapproving learning of the language or not being aware that there exist cultural differences, the later may incorporate suppositions that tactics at work are same everywhere. Aswatthapa provides examples of many companies who practiced and still practicing ethnocentric approaches in business. "Firms such as
Procter and Gamble Philips, NV and Matsushita originally followed the ethnocentric approach. In the Dutch firm Philips, for example all important positions in most foreign subsidiaries were at one time held by Dutch nationals who were referred to by their non Dutch colleagues and the Dutch mafia. In many Japanese and South Korean firms today such as Toyota, Matsushita and Samsung, key positions in international operations are still held by the home country nationals. According to the Japanese Overseas enterprises Associations in 1996 only 29 per cent of foreign Japanese companies had presidents who were not Japanese. In contrast 66 percent of the Japanese subsidiaries of foreign companies had Japanese presidents" (Aswatthapa 2005:646). Not only in the business arena, has the practice of ethnocentrism restricted our views towards being rational and sensitive but also it has largely impacted our thoughts and beliefs in the usual customs. Ferraro and Briody exemplify "whereas most Americans are repulsed by an Indonesian who blows his nose onto street, the Indonesian is repulsed by the American who blows his nose in a handkerchief and then carries it around for the rest of the day in his pocket; the Japanese consider the American practice of sitting in a bathtub full of dirty, soapy water to be best an ineffective way of bathing and at worst a disgusting practice; and East Africans think that American have no sense of hygiene because they defecate in rooms that are frequently located adjacent to that part of house where food is prepared" (Ferraro and Briody 2017:21). A lot of people across the globe practice ethnocentrism in some way or the other. Although ethnocentrism doles out positivity in making a group strong and robust, it surely "contributes to prejudice, contempt for outsiders and intergroup conflict" (21). 
Studies suggest that awareness of cultural differences can enhance our learning about different cultures and their practices. Although it may never completely eradicate our feelings against other cultures but it will facilitate us to curtail its unconstructive consequences. Business people mainly dealing with international business must abstain themselves from judgments and conclusions. Rather, they ought to inquire about and comprehend other people through their culture.

\section{Results and Discussion}

\section{Soft Skills to Overcome Cultural Stereotyping \&}

\section{Ethnocentrism}

Soft skills had been the most emerging and essential requirements in the recent decades mainly in business organizations. Studies effectively suggest that while technical skills or hard skills open an entry gate for employees in the business world, soft skills pave way to sustainability and success. The ability to deal with various situations and to maintain effective relationships with everyone around is one of the greatest significance of soft skills today. The broad skills set of soft skills include communication skills, managing skills, people skills, life skills, employability skills, personal management, relationship management, cultural competence and the list is endless. The study below demonstrates the significance of soft skills in overcoming cultural stereotyping and ethnocentrism in order to maintain harmony when dealing business internationally. Below are some of the crucial skills and abilities one must inculcate to overcome the barriers.

\section{Cultural Communication}

It is obvious that everything begins and ends with communication. Hence, communication also plays an important role in cross cultural communication. Communication does not simply include speaking and writing but also includes listening and reading. Body language like listening and speaking skills, use of space, time, touch and many more are essential components of non verbal communication that need consciousness and accountability. A lot of time wrong concepts arise when employees fail to connect with the non verbal elements of their interaction with their counterparts. Malan writes "the first ethical responsibility of the different cultural groups is to make an honest effort to understand each other's way of communication" (Malan 2001:209). Before anything, an attempt to communication solves a lot of differences be it cultural, perceptual or emotional and it is communication alone that fixes deals and services across organizations. Appropriately customized and well chosen words can in fact result in achieving farsighted goals among organizations. Learning languages, body languages, acquiring knowledge and setting proper code towards delivery to effective messages can further lead to effective cross cultural business communication.

\section{Cultural Sensitivity and Awareness}

"Arguably, tolerance and understanding of cultural differences are new soft skills for the modern age" (Funk 2017). In other words being culturally sensitive which implies an eager to know about other cultures and to be sensitive to other culture's view points. "Cultural sensitivity begins with the appropriate use of knowledge about people's cultural background combined with the ability to respond to intercultural processes with a range of interpersonal skills appropriate to effectively manage cultural differences" (Gurung 2014:xii). The outcome is 
sensitivity towards other cultures further results in positive response towards cultural change and adaptation which expands through the acquaintance of the artistic information and being able to defeat cultural barriers. Abilities to self judge and self awareness along with self evaluations towards cultural proficiencies, self organized to efficient rejoinder and self motivation to continue to learn more about cultures help in adapting cultural diversities. While learning regarding other cultures many doors get open to immeasurable experiences and enlarge our mindset.

\section{Cultural Adaptation}

Flexibility is one of the many skills that one can inculcate to adapt in any culture round the globe. It is the ability to learn the new settings and develop further abilities to acclimatize with the same effortlessly and to appreciate the learning process that comes in the process. It is also moving ahead without fear of losing self identity. Although the learning process is not easy as Molinsky describes "you can feel anxious and embarrassed about not knowing exactly how to behave and inauthentic and disingenuous bout how awkward and unnatural it feels. You can feel frustrated and annoyed about having to adapt in the first place" (Molinsky 2013: ii). However, the fact is the more one feels uneasy the more foreign cultures make them feel mismanaged. Hence, one needs to first learn about new culture and blend impeccably so as to avoid hazards. Learning about other cultures opens doors to and enlarge our minds to countless apparitions to uncover differences and commonalities across cultures.

\section{Cultural Mutuality}

The incorporation of affinity and respect for each other's culture holds close the many difference of views, opinions, beliefs, values and also arouses willingness to be open minded to cultural behavior among people. Bias free, non- prejudice attitude, fairmindedness, appreciation and understanding are some of the important skills towards practicing mutuality and respect for cultural differences. Woodside discusses that "a relationship has mutuality when a one party's behavior is expected to be similar to the other because of their mutual dependence. Conversely, if within the business interaction one arty commonly sees only its own interests, ignoring the value of the counterpart, this denotes a lack of mutuality and it is less likely that a relationship will be built. Instead the exchange will tend to stay transactional" (Woodside 2010: 84). Hence it is a two-way process that can result in empathy, respect and increase the chances of better understanding.

\section{Conclusion}

This paper studied cross cultural communication as an important element in international business. The paper also focused on the barriers that obstruct the communication across cultures. Further, it delved into the various aspects of soft skills to enhance culture competence to fight with the barrier and make constructive approach towards cross cultural communication. The paper concluded that developing essential skills and abilities towards cultural management is the nee of the hour for successful transactions of business across borders. Cultural assumptions and cultural superiority discourage understanding, perseverance and compromise. Inculcating and practicing soft skills primarily while facing cultural diversities is non-aggressive or 
intimidating rather it concedes and corroborates people from various culture while still improving self. Culturally competent organizations tend to change the views of their employees towards employees of different organization from different cultures, encourage the contributions of each culture and celebrate the productive consequences after communicating with different cultures and embracing cultural diversity.

\section{References}

Aswathappa, K. (2005). Human Resources and Personnel Management. New Delhi: TataMc Graw-Hill

Carroll, C. E (2016). The Sage Encyclopedia of Corporate Reputation. USA: Sage

Cooley, C. H. (1998). On self and social organization. Chicago: The University of Chicago Press.

Dlaby, L. and Scott, J. C (2010). International Business. USA: Cengage Learning

Ferraro, G. P. and Briody, E. K (2017). The Cultural Dimension of Global Business. New York: Routledge

Funk, C. 2017, February 23. Soft Skills: Accepting and Understanding Cultural Differences. Assessed October 6, 2018, from http://bookboon.com/blog/2017/02/soft-skillsaccepting-understanding-cultural-differences/

Gerritsen, M. 2018. The Role of Culture in communication: How knowledge of differences in communication between cultures may be the key to successful intercultural communication", South African Journal of Linguistics, Vol. 16, Issu Sup 35 , p.28.

Goldman, B. M. (2012). The psychology of negotiations in the 21 st century workplace new challenges and new solutions. New York: Psychology Press.

Gonzalez, M. D. 2011. February 3. Cross cultural Vs Inter Cultural Assessed October 14, 2018 from https://ixmaticommunications.com/2011/02/03/ cross-cultural-vs-intercultural/

Gudykunst, W. B. 2003. Cross cultural communication and Intercultural communication. California: Sage

Gurung, A. R (2014). Multicultural Approaches to Health and Wellness in America.USA: Praegar.

Hartley, P., \& Bruckmann, C. (2002). Business Communication. New York: Routledge.

Laroche, L. (2014). Danger and opportunity: bridging cultural diversity for competitive advantage. Place of publication not identified: Routledge.

Lehman, C. M., \& DuFrene, D. D. (2008). Business Communication. Boston, MA: South-Western.

Malan, F., \& Smit, B. (2001). Ethics and leadership in business and politics. Lansdowne: Juta.

Maude, B. (2016). Managing cross-cultural communication: principles and practice. London: Macmillan Education.

Means, T. L., \& Rankin, D. S. (2010). Business communication. Australia: South-Western Cengage Learning.

Merkin, R. S. (2018). Saving face in business managing cross-cultural interactions. New York, NY: Palgrave Macmillan.

Molinsky, A. (2013). Global Dexterity: How to Adapt Your Behavior across Cultures without Losing Yourself in the Process. Boston: Harvard Business Review Press.

Neulip, J. W. 2017. Intercultural Communication: A Contextual Approach. Los Angeles: Sage 
Niemeier, S., Campbell, C. P., \& Dirven, R. (1998).

The cultural context in business communication. Amsterdam: Benjamins.

Rosengren, K. E. (2000). Communication: an introduction. London: Sage Publications.

Staw and Kramer (2005). Research in Organizational Behavior: An Annual Series of Analytical Essays and Critical Reviews. USA: Elsevier

Steers, R. M., Nardon, L., \& Sánchez-Runde, C. (2011). Management Across Cultures: Challenges And Strategies. Cambridge: Cambridge Univ. Press.

Ting-Toomey, S., Gu, L., \& Chi, R. (2007). Communicating Across Cultures. Shanghai: Shanghai Foreign Language Education Press.

Woodside, A. G. (2010). Organizational Culture, Business-to-Business Relationships and Interfirm Networks. Boston: Emerald Group Publishing 